\title{
Regional anesthesia during the COVID-19 pandemic: a time to reconsider practices? (Letter \#2)
}

\author{
Julian Aliste, MD • Fernando R. Altermatt, MD, MHSc, MBA (D) Rous Atton, MD • \\ Daneila Bravo, MD • Sebastian Layera, MD • Pablo Miranda, MD • \\ Italo Pesce, MD
}

Received: 4 April 2020/Revised: 14 April 2020/Accepted: 15 April 2020/Published online: 1 May 2020

(c) Canadian Anesthesiologists' Society 2020

\section{To the Editor,}

We read with interest the article by Lie et al. addressing the "Practical considerations for performing regional anesthesia: lessons learned from the COVID-19 pandemic". 1 Latin America has begun facing the coronavirus disease (COVID-19) pandemic with the great advantage of the experience and knowledge already gained in the northern hemisphere, particularly in Asia and Europe. The brief review by Lie et al. is therefore highly welcome and paramount to us.

Our country is at the beginning of the outbreak, and the Chilean Society of Anesthesiology is preparing a clinical response for the oncoming difficult times. As members of its regional anesthesia (RA) committee, we have collected information and developed local recommendations to guide our colleagues in handling surgical procedures under RA in COVID-19 patients. $^{2}$

It is in this spirit that we wish to comment on some aspects of the suggestions made by Lie et al. to discuss, clarify, and reinforce them. One of the main objectives in the management of COVID-19 patients is to protect the

This letter is accompanied by a reply. Please see Can J Anesth 2020; this issue.

J. Aliste, MD - D. Bravo, MD - S. Layera, MD

Universidad de Chile, Santiago, Chile

F. R. Altermatt, MD, MHSc, MBA ( $₫)$ · P. Miranda, MD Pontificia Universidad Catolica de Chile, Santiago, Chile

e-mail: falterma@uc.cl

R. Atton, MD

Hospital Barros Luco Trudeau, Santiago, Chile

I. Pesce, MD

Hospital de Urgencia de la Asistencia Publica, Santiago, Chile safety of healthcare workers. There are some recognized potential advantages of RA over general anesthesia (GA). Nevertheless, for RA to be a viable alternative to GA, it must guarantee adequate surgical conditions (i.e., with minimal risk of failure), ensure patient safety, and provide consistent protection for health workers.

We suggest that the review by Lie at al. could have been improved by having more consistent recommendations for personal protective equipment (PPE) and patient oxygen therapy, and more precise specifications regarding the optimal approaches to upper extremity blocks.

As a Committee, we strongly feel that anesthesiologist's PPE used for RA must be the same as that for GA as it is impossible exclude the need for an emergent airway intervention during the procedure. Thus, recommending a higher level of PPE for the transport of patients than during the RA case itself is questionable. Furthermore, the statement by Lie et al. that "donning an N95 respirator or powered air-purifying respirator is discretional during RA" also does not seem optimal.

Our group suggests that in this patient population, the goal should be a cooperative and lightly sedated patient with spontaneous breathing (and always wearing a surgical mask). Therefore, the need for a face mask instead of a nasal cannula might raise questions as to the real benefit of RA over GA.

Finally, special attention should be given to patients with respiratory compromise needing upper extremity surgeries. Brachial plexus blocks above the clavicle carry an inherent risk of phrenic nerve palsy, which translates to a consequent risk of up to $25 \%$ decrease in vital capacity and forced expiratory volume. ${ }^{3}$ Unfortunately, no reduction in either local anesthetic volume or concentration has consistently reduced the risk of hemi-diaphragmatic paresis below $20 \%$, without increasing the risk of block failure. ${ }^{4}$ 
Hence, we strongly recommend performing diaphragmsparing alternatives, such as a suprascapular nerve block, with or without axillary nerve block $^{5}$ (or no block at all) for these patients.

\section{Disclosures None.}

Funding statement None.

Editorial responsibility This submission was handled by Dr. Hilary P. Grocott, Editor-in-Chief, Canadian Journal of Anesthesia.

\section{References}

1. Lie SA, Wong SW, Wong LT, Wog TG, Chong SY. Practical considerations for performing regional anesthesia: lessons learned from the COVID-19 pandemic. Can J Anesth 2020; DOI: https:// doi.org/10.1007/s12630-020-01637-0.
2. Aliste $J$, Altermatt $F$, Atton $R$, et al. Recomendaciones para la ejecución de anestesia regional no obstétrica en perioperatorio de pacientes COVID-19 (Chilian). Revista Chilena de Anestesia 2020; DOI: https://doi.org/10.25237/revchilanestv49n03.08.

3. Urmey $W F$, McDonald $M$. Hemidiaphragmatic paresis during interscalene brachial plexus block: effects on pulmonary function and chest wall mechanics. Anesth Analg 1992; DOI: https://doi. org/10.1213/00000539-199203000-00006.

4. Tran DQ, Layera S, Bravo D, Cristi-Sanchez I, Bermudez L, Alistye A. Diaphragm-sparing nerve blocks for shoulder surgery, revisited. Reg Anesth Pain Med 2020; DOI: https://doi.org/10. 1136/rapm-2019-101259.

5. Toma O, Persoons B, Pogatzki-Zahn E, et al. PROSPECT guideline for rotator cuff repair surgery: systematic review and procedure-specific postoperative pain management recommendations. Anaesthesia 2019; 74: 1320-31.

Publisher's Note Springer Nature remains neutral with regard to jurisdictional claims in published maps and institutional affiliations. 